\title{
DOS NUEVAS ESPECIES DE PINGUICULA (LENTIBULARIACEAE) DEL CENTRO Y NORTE DE MEXICO'
}

\author{
SERGIO Zamudio \\ Coordinación de Ecología del Centro de Investigación y Desarrollo del Estado de \\ Michoacán. Apartado postal 386; 61600 Pátzcuaro, Mich. México
}

\section{RESUMEN}

Se describen dos especies nuevas de Pinguicula de México: P. crassifolia (Subg. Pinguicula) de Las Ventanas, municipio de El Chico, Hidalgo y P. gracilis (Subg. Temnnoceras) del Cerro de las Mitras, municipio de Monterrey, Nuevo León.

\begin{abstract}
Two new species of Pinguicula are described from Mexico: P. crassifolia (Subg. Pinguicula) from Las Ventanas, municipality of El Chico, Hidalgo, and $P$. gracilis (Subg. Temnoceras) from Cerro de las Mitras, municipality of Monterrey, Nuevo León.
\end{abstract}

Las especies descritas en este trabajo permanecieron confundidas con otras durante varios años; el estudio detallado de los especímenes disponibles en los herbarios, más colectas adicionales con observaciones en campo y en cultivo nos han permitido ubicarlas correctamente y proponerlas como especies nuevas.

\section{Pinguicula crassifolia sp. nov.}

Herba perennis. Folia dimorpha, in duabus seriebus disposita; folia "aestivalia" 5-7, petiolata, laminae ellipticae usque ad oblongae, apice rotundatae, basi cuneatae usque ad rotundatae, margine leviter involutae, $37-111 \mathrm{~mm}$ longae, (16) 20-60 mm latae, petioli villosi, vix ciliati; folia "hiemalia" 20-60, crassa, dolabriformia, elliptica usque ad anguste obtrullata, apice acuta, margine integra, apicem versus ciliata, 3-11 mm longa, 1.5-6 mm lata. Pedicelli 1-4, erecti, glanduloso-hirsuti, $47-85 \mathrm{~mm}$ longi. Flores $23-50 \mathrm{~mm}$ longi (calcare incluso); calyx bilabiatus, villosus, labium superum 1/2-7/8 longitudinis trilobum, lobis triangularibus usque ad triangulari-lanceolatis, (1.5) 2-3.5 mm longis, 1-2(3) $\mathrm{mm}$ latis, labium inferum usque ad basim fere bipartitum, lobis lanceolatis vel oblongis, 2-3(4) mm longis, 1-2 mm latis; corolla bilabiata, rubro-purpurea, labium superum bilobatum, lobis obovato-cuneatis, apice truncatis vel rotundatis, (5)7-12 mm longis, 4-11 mm latis, labium inferum trilobatum, lobis obovato-cuneatis, apice truncatis vel rotundatis, $6-15 \mathrm{~mm}$ longis, (4)5-12.5 mm latis, lobus medius lateralibus paulo major, tubus infundibuliformis, leviter ventricosus, $8-15 \mathrm{~mm}$ longus, 3-6(10) $\mathrm{mm}$ latus, intus ventraliter dense pubescens, pilis multicellularibus dimorphis, in tubi parte supera pilis cylindricis, longis, tenuibus, aliquis apice biseriatis, in parte media et infera pilis brevibus, crassis,

'Este trabajo fue realizado con el apoyo del Consejo Nacional de Ciencia y Tecnología. 
aliquis apice biseriatis vel multiseriatis, palatum nullum, calcar cylindricum-subulatum, $8-25 \mathrm{~mm}$ longum, 1-2 mm latum; stamina 2-2.7 mm longa. Capsula subglobosa vel late ovoidea, 3-4 mm diametro. Semina fusiformia, $\pm 1 \mathrm{~mm}$ longa, $\pm 0.2 \mathrm{~mm}$ lata, superficie reticulata, cellulis polygonalibus (Fig. 1).

Hierba perenne, de 7 a $11 \mathrm{~cm}$ de alto. Hojas dimórficas, en dos series; las de "verano" escasas (5 a 7), pecioladas, de 37 a $111 \mathrm{~mm}$ de largo, por (16) 20 a $60 \mathrm{~mm}$ de ancho, lámina elíptica a oblongo-elíptica, ápice redondeado, base cuneada a redondeada, margen ligeramente involuto, glanduloso-viscosa en el haz, hasta $65 \mathrm{~mm}$ de largo, peciolo viloso, con el margen escasamente ciliado, hasta $45 \mathrm{~mm}$ de largo; hojas de "invierno" crasas, presentes durante la floración, numerosas (20 a 60), dolabriformes, elípticas a estrechamente obtruladas en contorno, ápice agudo, margen entero, ciliado hacia el ápice, glandulosas en el haz, de 3 a $11 \mathrm{~mm}$ de largo, por 1.5 a $6 \mathrm{~mm}$ de ancho. Pedicelos 1 a 4 por planta, erectos, glandularhirsutos, de 47 a $85 \mathrm{~mm}$ de largo, por $\pm 1 \mathrm{~mm}$ de ancho. Flores de 23 a $50 \mathrm{~mm}$ de largo (incluyendo el espolón), por (13) 20 a $30 \mathrm{~mm}$ de ancho, cáliz bilabiado, viloso, el labio superior dividido de $1 / 2$ a $7 / 8$ de su longitud en tres lóbulos triangulares a triangular-lanceolados, de (1.5) 2 a $3.5 \mathrm{~mm}$ de largo, por 1 a 2 (3) $\mathrm{mm}$ de ancho, labio inferior dividido casi hasta su base en dos lóbulos lanceolados u oblongos, de 2 a 3 (4) $\mathrm{mm}$ de largo, por 1 a $2 \mathrm{~mm}$ de ancho; corola bilabiada, rojo-purpúrea, el labio superior dividido en dos lóbulos obovado-cuneados, con el ápice truncado o redondeado, de (5) 7 a $12 \mathrm{~mm}$ de largo, por 4 a $11 \mathrm{~mm}$ de ancho, el labio inferior un poco más grande que el superior, dividido en tres lóbulos obovado-cuneados, ápice truncado o redondeado, de 6 a $15 \mathrm{~mm}$ de largo, por (4) 5 a $12.5 \mathrm{~mm}$ de ancho, el lóbulo medio es un poco más grande que los laterales; tubo infundibuliforme, ligeramente ventricoso, de 8 a $15 \mathrm{~mm}$ de largo, por 3 a 6 (10) $\mathrm{mm}$ de ancho, densamente pubescente en su interior en la región ventral, con dos tipos de pelos multicelulares, los de la parte superior son cilíndricos, largos y delgados, algunos biseriados en el ápice, los de la parte media inferior son cortos, gruesos, algunos biseriados a multiseriados en el ápice, paladar no desarrollado, espolón cilíndrico-subulado, sin diferenciarse del tubo de la corola, recto o formando un ángulo de $160^{\circ}$ con la corola, de 8 a 25 $\mathrm{mm}$ de largo, por 1 a $2 \mathrm{~mm}$ de ancho, estambres de 2 a $2.7 \mathrm{~mm}$ de largo, ovario elipsoidal, con pelos glandulares multicelulares. Cápsula subglobosa a ampliamente ovoide, de 3 a $4 \mathrm{~mm}$ de diámetro. Semillas fusiformes, con apéndices ensanchados en sus extremos, de $\pm 1 \mathrm{~mm}$ de largo, por $\pm 0.2 \mathrm{~mm}$ de ancho, superficie reticulada con celdas poligonales.

TIPO: MEXICO. Hidalgo, municipio de El Chico, Las Ventanas, en zona contigua al bosque de Abies, alt. 3000 m, 11.IV.1976, Miguel Medina C. 316 (HOLOTIPO: ENCB. ISOTIPOS: IEB, MEXU, identificados originalmente como $P$. macrophylla).

Material adicional examinado: MEXICO, Hidalgo: Cerro de las Ventanas, cerca del albergue, municipio de El Chico, bosque de Abies, crece sobre musgos en las rocas húmedas, alt. $2950 \mathrm{~m}, 9 . \mathrm{VI} .1981, \mathrm{M}$. Cervantes 342 (ENCB); Las Ventanas, $6 \mathrm{~km}$ al N de Pachuca, municipio de El Chico, sobre peñascos en zona húmeda y sombreada, alt. $2950 \mathrm{~m}, 17 . \mathrm{IV} .1983$, M. Medina C. 2382 (ENCB); Parque Nacional El Chico, $3 \mathrm{~km}$ al NO de Pueblo Nuevo, municipio de Mineral del Chico, bosque de Abies religiosa y Juniperus monticola suelo no muy profundo, rico en materia orgánica, alt. $2900 \mathrm{~m}, 22 . \mathrm{IV} .1984$, Abisai G. Mendoza y F. Mérida 1419 (MEXU); Las Ventanas, municipio de El Chico, sobre las peñas, en sitios húmedos, alt. 2950 m, 27.IV.1986, S. Zamudio 3875(ENCB, IEB, MEXU); Ibid., 24.V.1987, S. Zamudio 5226 
Zamudio: Dos Nuevas Especies de Pinguicula
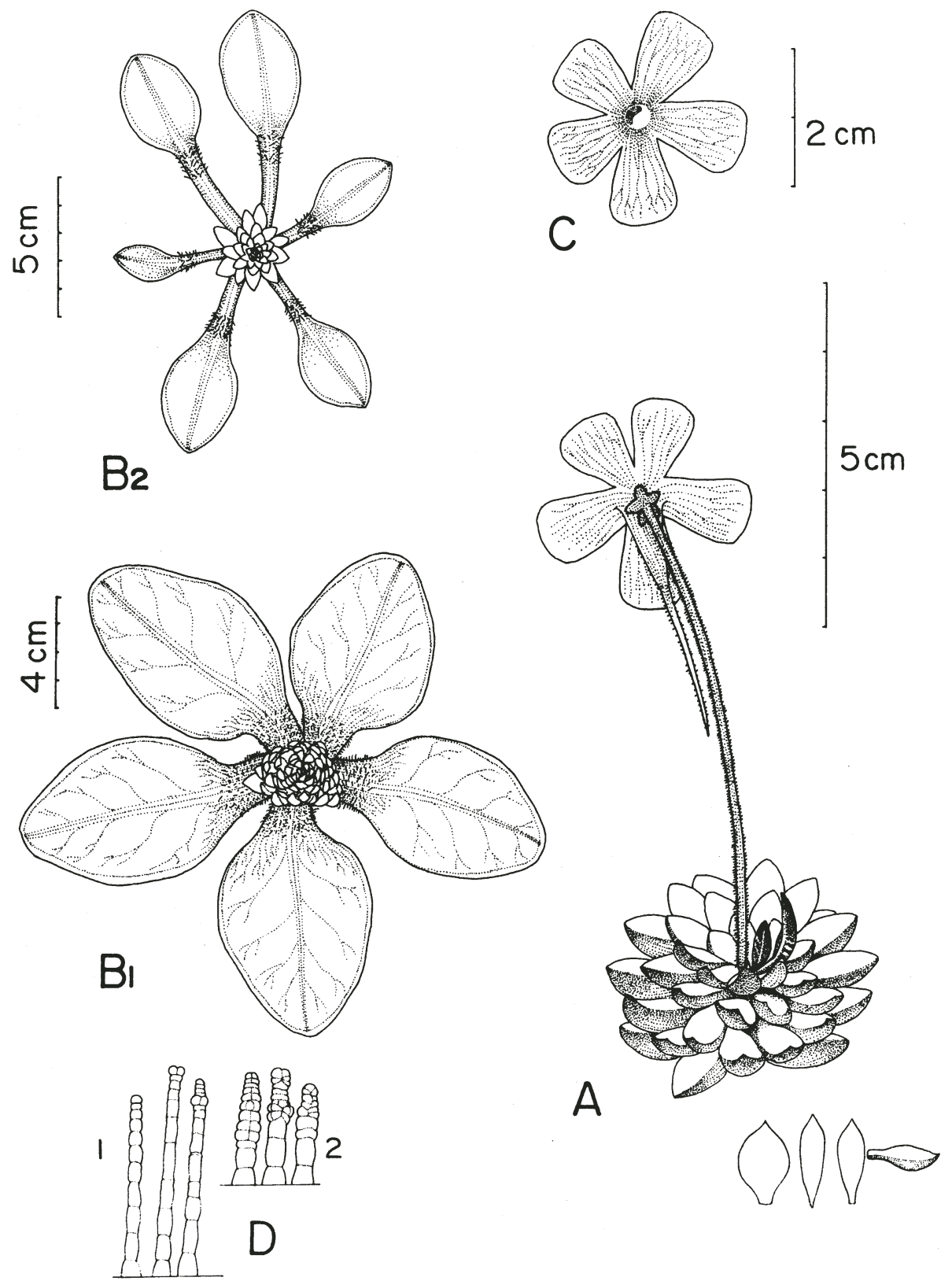

Fig. 1. Pinguicula crassifolia Zamudio. A. Planta en floración con roseta de "invierno"; se muestra la variación en el contorno de las hojas; $B_{1}$. Roseta de "verano" con restos de la roseta de "invierno", planta sometida a condiciones de luz directa y sol en cultivo; $B_{2}$. Roseta de "verano" con restos de la roseta de "invierno", planta sometida a condiciones de sombra constante en cultivo; C. Lóbulos de la corola; D. Pelos del interior del tubo de la corola: 1. pelos de la parte superior, 2. pelos de la parte inferior del tubo. 
(ENCB, IEB, MEXU); Cortinas de la Bruja, $1.5 \mathrm{~km}$ de Mineral El Chico, municipio de El Chico, sobre peñas en cañadas con bosque de Abiesy Quercus, alt. 2850 m, 20.III.1988, M. A. Barrios y M. Medina 3425 (ENCB, IEB).

P. crassifolia sólo se conoce del Cerro de las Ventanas y sus alrededores en el municipio de El Chico, Hidalgo, en el extremo norte del Valle de México; crece sobre musgos y materia orgánica acumulada en las peñas, en bosque de Abies religiosa, entre 2850 y 3000 m de altitud.

Florece de fines de marzo a principios de junio, cuando presenta la roseta de "invierno"; los frutos maduros se encuentran hacia finales de mayo, al tiempo que las hojas de verano empiezan a crecer, éstas alcanzan su máxima talla en agosto; en este mes las hojas de invierno empiezan a crecer de nuevo y en septiembre ya están bien desarrolladas, al tiempo que las hojas de verano empiezan a secarse.

Esta especie pertenece al subgénero Pinguicula (Casper, 1962), por presentar la corola claramente bilabiada, con los lóbulos enteros de color púrpura, el tubo infundibuliforme sin paladar, el espolón de igual o mayor tamaño que el tubo y dos tipos de rosetas. Dentro de este subgénero, se ubica cerca de las especies de la sección Orcheosantes A. DC., con las que coincide en la mayoría de sus características, pero difiere por el tubo largamente infundibuliforme, ligeramente ventricoso, igual o casi igual en longitud a los lóbulos de la corola; mientras que en la diagnosis de la sección mencionada el tubo se describe como cortísimo, ampliamente infundibuliforme y los lóbulos de la corola lo superan por mucho en longitud.

Desde que se colectó por primera ocasión $P$. crassifolia, fue confundida con $P$. macrophylla HBK., con la que tiene mucha semejanza, pero que al parecer no se encuentra en el Valle de México. Cervantes (1985) al revisar el género para el Valle de México no se dió cuenta de este error e incluyó los especímenes de Medina 1316, 2382 y Cervantes 342 en $P$. macrophylla.

Si bien las dos especies son muy parecidas y pueden confundirse con facilidad en ejemplares de herbario, la revisión detallada de los especímenes y sobre todo la observación en el campo muestran claras diferencias. En Pinguicula crassifolia el tubo es largamente infundibuliforme, ligeramente ventricoso y se continúa gradualmente con el espolón sin mostrar una reducción abrupta de su diámetro, las hojas de invierno son crasas, dolabriformes, elípticas a estrechamente obtruladas en contorno y forman una roseta abierta (Fig. 1), las hojas de verano son pecioladas, elípticas a oblongo-elípticas, con el peciolo viloso en la parte superior y escasamente ciliado. En Pinguicula macrophylla el tubo de la corola es cortísimo, infundibuliforme, se reduce bruscamente hacia su base y da paso después de una constricción al espolón cilíndrico, las hojas de invierno son ampliamente ovadas a ovado-lanceoladas, acuminadas a largamente acuminadas, de 8 a $16 \mathrm{~mm}$ de largo, están fuertemente apretadas entre sí formando una especie de bulbo que permanece enterrado durante el invierno, finalmente las hojas de verano son pecioladas, ovado-suborbiculares a elípticas con el peciolo no viloso ni ciliado.

También las separa la fecha de floración y su comportamiento fenológico: $P$. crassifolia florece desde finales de marzo hasta principios de junio y fructifica a finales de mayo, mientras mantiene las hojas de invierno; por su parte $P$. macrophylla florece desde fines de junio hasta principios de septiembre, cuando tiene hojas de verano.

La distribución y el habitat que ocupan es diferente: $P$. crassifolia sólo se ha colectado en el Cerro de Las Ventanas y sus alrededores en el municipio de El Chico, Hidalgo, en bosque de Abies religiosa entre 2850 y 3000 m de altitud; en cambio, a $P$. macrophylla se le conoce de San Luis Potosí, Guanajuato, Querétaro y Michoacán, en bosque de encinos o de pino-encino, 
entre (1500) 2000 y $2500 \mathrm{~m}$ de altitud (Fig. 2).

La presencia de $P$. macrophylla en El Chico, Hidalgo, es dudosa, pues aunque Casper (1966) cita un ejemplar de Martínez 15062-S, no lo hemos visto y no se ha comprobado recientemente su presencia en la zona. Por otra parte en los herbarios mexicanos no existe otro registro de esta localidad o sus cercanias para la especie.

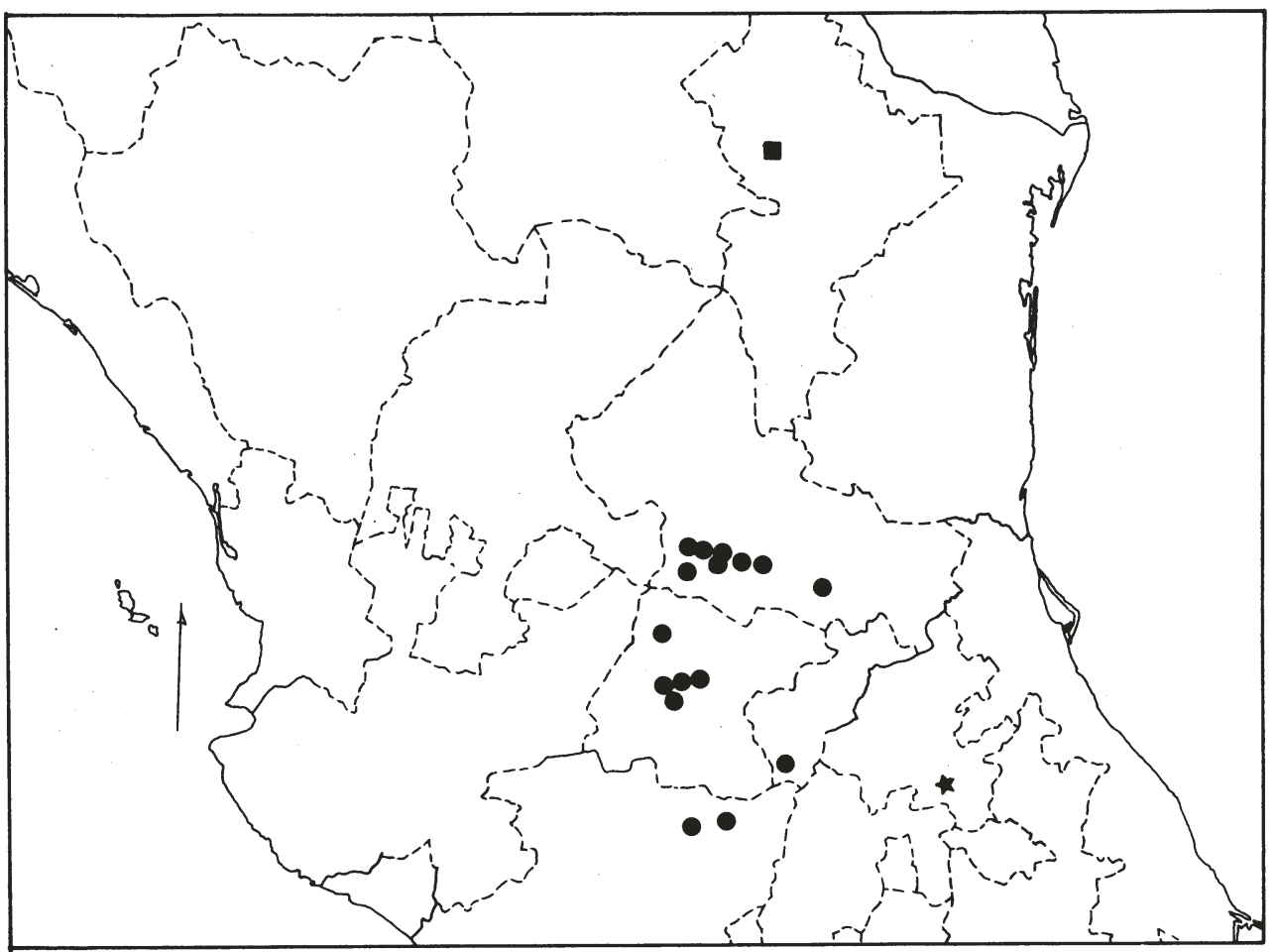

Fig. 2. Mapa del centro de la República Mexicana que muestra la distribución conocida de: $P$. crassifolia (estrella), P. macrophylla (puntos) y P. gracilis (cuadro).

Pinguicula gracilis sp. nov.

Herba perennis (?). Folia dimorpha, in duabus seriebus disposita; folia "hiemalia" 10-35, spathulata usque ad oblanceolata, apice rotundata, margine ciliata, 3-12 mm longa, 1.5-4 mm lata; folia "aestivalia" 5-15, spathulata usque ad obovato-spathulata, apice rotundata, margine integra, leviter involuta, 8-16 mm longa, 4-10 mm lata. Pedicelli 1-4, purpurei, glabrescentes, 18 $57 \mathrm{~mm}$ longi. Flores 10-19 mm longi (calcare incluso); calyx purpureus, bilabiatus, labium superum usque ad basim tripartitum, lobis ellipticis vel oblongis, (1.3)2-3 mm longis, labium inferum 3/4-5/6 longitudinis bipartitum, lobis ellipticis vel oblongis, 1.3-2(2.6) mm longis; corolla 
bilabiata, alba, sed faucibus et venarum basibus purpureis et labii inferi lobulo medio macula luteo-virescenti ornato, labium superum bilobatum, lobi oblongi apice rotundato vel truncato, (3.5)4-7 mm longi, 2.2-5.5 mm lati, labium inferum inaequaliter trilobatum, lobi laterales obovati vel oblongi, apice rotundato vel truncato, 3.1-7 mm longi, (1.5)2-4.8 mm lati, lobus medius lateralibus notabiliter longior, obovato-spathulatus, apice emarginatus, pilorum multicellularium penicillio in macula lutea munitus, $5.5-11.5 \mathrm{~mm}$ longus, $3-11 \mathrm{~mm}$ latus, tubus infundibuliformis, (1.5)2-4 mm longus, 3-6 mm latus, intra pilis multicellularibus subulatis tectus, palatum nullum, calcar cylindricum, subulatum, atrovirens, intra pilis multicellularibus cylindricis, brevibus, retrorsis, tectum, 3-6.5 mm longum, 0.5-1 mm latum; stamina $\pm 2 \mathrm{~mm}$ longa. Capsula subglobosa vel botuliformis, umbilicata, 1-2.5 mm diametro, glanduloso-pubescens. Semina fusiformia, superficie reticulata (Fig. 3 ).

Hierba perenne (?), de 2.4 a $7.8 \mathrm{~cm}$ de alto. Hojas dimórficas, en dos series, las de "invierno" presentes durante la floración, numerosas (10 a 35), espatuladas a oblanceoladas, ápice redondeado, pubescentes en la parte apical, de 3 a $12 \mathrm{~mm}$ de largo, por 1.5 a $4 \mathrm{~mm}$ de ancho; hojas de "verano" pocas (5 a 15), espatuladas a obovado-espatuladas, ápice redondeado, margen entero, ligeramente involuto en el ápice, glanduloso-viscosas en el haz, de 8 a $16 \mathrm{~mm}$ de largo por 4 a $10 \mathrm{~mm}$ de ancho. Pedicelos 1 a 4 por planta, morados, erectos, glabrescentes, de 18 a $57 \mathrm{~mm}$ de largo, por 0.3 a $1 \mathrm{~mm}$ de ancho. Flores de 10 a $19 \mathrm{~mm}$ de largo (incluyendo el espolón), por 7 a $16 \mathrm{~mm}$ de ancho, cáliz morado, bilabiado, con glándulas estipitadas dispersas, superficie exterior granular, el labio superior dividido casi hasta su base en tres lóbulos elípticos u oblongos, de (1.3) 2 a $3 \mathrm{~mm}$ de largo, por (0.6) 1 a $1.6 \mathrm{~mm}$ de ancho, el labio inferior dividido de $3 / 4$ a 5/6 de su longitud en dos lóbulos elípticos u oblongos, de 1.3 a 2 (2.6) $\mathrm{mm}$ de largo, por 0.6 a $1.2 \mathrm{~mm}$ de ancho; corola bilabiada, blanca con la garganta y la base de las venas moradas y una mancha amarillo-verdosa en la base del lóbulo medio del labio inferior, el labio superior dividido en dos lóbulos oblongos, ápice redondeado a truncado, de (3.5) 4 a $7 \mathrm{~mm}$ de largo, por 2.2 a $5.5 \mathrm{~mm}$ de ancho, el labio inferior dividido en tres lóbulos desiguales, los lóbulos laterales obovados a oblongos, ápice redondeado a truncado, de 3.1 a $7 \mathrm{~mm}$ de largo, por (1.5) 2 a $4.8 \mathrm{~mm}$ de ancho, el lóbulo medio notablemente más largo que los demás, obovado-espatulado, con el ápice emarginado, con un mechón de pelos multicelulares largos en la base, sobre la mancha amarilla, de 5.5 a $11.5 \mathrm{~mm}$ de largo, por 3 a $11 \mathrm{~mm}$ de ancho, tubo infundibuliforme, de (1.5) 2 a $4 \mathrm{~mm}$ de largo, por 3 a $6 \mathrm{~mm}$ de ancho, con pelos multicelulares subulados en su interior, más cortos que los del labio inferior, paladar ausente, espolón cilíndrico-subulado, verde oscuro, con pelos multicelulares cilíndricos, cortos y retrorsos en su interior, de 3 a $6.5 \mathrm{~mm}$ de largo, por 0.5 a $1 \mathrm{~mm}$ de ancho, sin formar un ángulo aparente con la corola, estambres de $\pm 2 \mathrm{~mm}$ de largo, ovario hemisférico, glandular-pubescente. Cápsula subglobosa o butiliforme, umbilicada, de 1 a $2.5 \mathrm{~mm}$ de diámetro, glandularpubescente. Semillas fusiformes, con apéndices ensanchados en sus extremos, superficie reticulada.

TIPO: MEXICO. Nuevo León, municipio de Monterrey, ladera norte del Cerro de las Mitras, sobre rocas calizas en taludes muy escarpados, en bosque de encinos, alt. $1450 \mathrm{~m}$, 19.II.1987, S. Zamudio y S. González 5184 (HOLOTIPO: IEB. ISOTIPOS: CHAPA, ENCB, MEXU).

Material adicional examinado: MEXICO, Nuevo León, municipio de Monterrey, Cerro de 

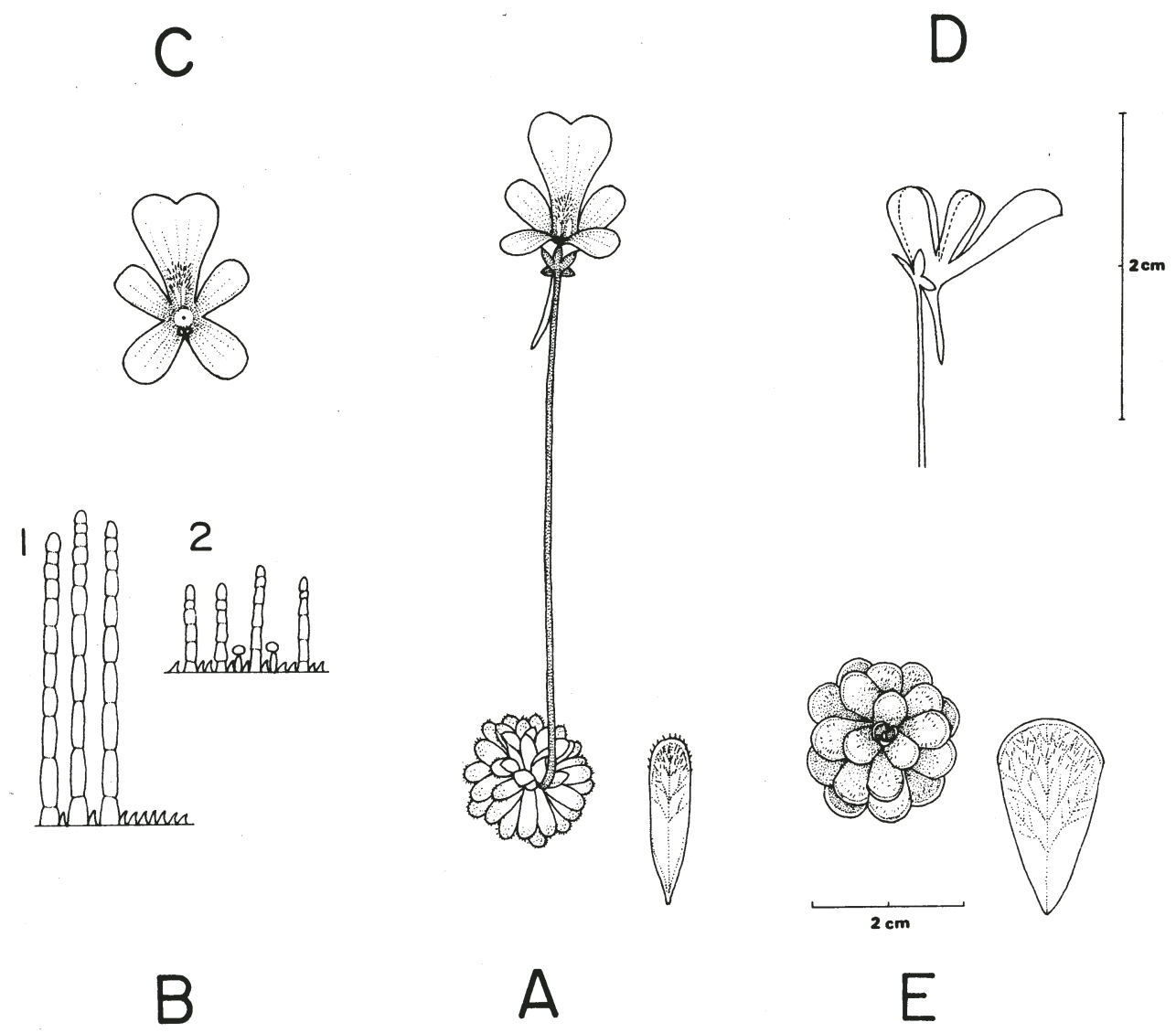

Fig. 3. Pinguicula gracilis Zamudio. A. Planta en floración con roseta de "invierno", se muestra detalle de la hoja; B. Pelos de la corola: 1. pelos de lóbulo medio del labio inferior, 2. pelos del espolón; C. Lóbulos de la corola; D. Vista lateral de la flor; E. Roseta de "verano" con detalle de la hoja. 
las Mitras, sobre colonias de briofitas en bosque de Cupressus lindleyi, alt. $1800 \mathrm{~m}, 12.11 .1980$, E. Ramirez-Alvarez 248 (CHAPA, UNL, identificado originalmente como $P$. aff. pumila Michx.); lbid., bosque de encinos, alt. $1000 \mathrm{~m}, 20 . X \mathrm{II} .1980, H$. Milonas s.n. (UNL, ejemplar estéril).

Esta especie fue confundida originalmente con $P$. pumila Michx., del subgénero Isoloba Barnh. emend. Casper, del SE de Estados Unidos y que hasta la fecha no se conoce de México. Si bien el espolón cilíndrico y largo con respecto al tubo de la corola recuerda a las especies de este subgénero, particularmente de la sección Agnata Casper; difiere de él por presentar dos tipos de hojas en rosetas subsecuentes y la corola claramente bilabiada.

Por la forma de la corola tiene un gran parecido con $P$. vulgaris $L$., del subgénero Pinguicula, pero pertenece en realidad al subgénero Temnoceras Barnh. emend. Casper, por presentar la combinación de las siguientes características: dos tipos de hojas en rosetas subsecuentes, corola bilabiada, el labio inferior más grande que el superior, el lóbulo medio del labio inferior más grande que los laterales y con el ápice emarginado, espolón cilíndrico o subcilíndrico.

Pinguicula gracilis no se ubica con exactitud en ninguna de las secciones o subsecciones descritas del subgénero mencionado; con la sección Ampullipalatum Casper, coincide por presentar dos tipos de rosetas, corola bilabiada, lóbulos rara vez enteros, labio inferior mayor, tubo cónico, pero difiere en tener un espolón cilíndrico o subcilíndrico y no presentar paladar. Con la sección Micranthus Casper (1962) coincide por la corola bilabiada, el labio inferior mucho mayor que el superior, el lóbulo intermedio mucho mayor que los laterales y frecuentemente emarginado, tubo cónico y espolón subcilíndrico, pero difiere en presentar dos tipos de hojas en rosetas subsecuentes.

Por sus características se encuentra más cerca de la sección Micranthus, pero su ubicación definitiva queda pendiente hasta que se tenga un mejor conocimiento del género en México.

Existe la duda de si se debe considerar a esta especie perenne, ya que todas las plantas colectadas en febrero de 1987 para cultivarse en Pátzcuaro, Michoacán, murieron durante el invierno de este año.

\section{AGRADECIMIENTOS}

Se agradece al Dr. J. Rzedowski la elaboración de la diagnosis latina para las nuevas especies, así como las sugerencias y comentarios al texto, a la Dra. Socorro González E. por su entusiasta ayuda en el campo. También se agradece la amabilidad de los encargados de los herbarios CHAPA, ENCB y UNL, por haber facilitado en préstamo sus ejemplares del género Pinguicula.

\section{LITERATURA CITADA}

CASPER, S.J. 1962. Revision der Gattung Pinguicula in Eurasien. Repert. Spec. Nov. 66 (1/2): 1-148. CASPER, S.J. 1966. Monographie der Gattung Pinguicula L. Bibliotheca Botanica 31(127/128): 1-209. CERVANTES, M. 1985. Lentibulariaceae. In: Rzedowski y Rzedowski. Flora Fanerogámica del Valle de México. Vol. II. Publ. 15. Instituto de Ecología, A.C. pp. 371-373. 


\section{FE DE ERRATAS}

En el artículo "Dos nuevas especies de Pinguicula (Lentibulariaceae) del centro y norte de México" de Sergio Zamudio, publicado en el número 3 , dice en el tercer párrafo, segunda línea de la pág. 22: "... Miguel Medina C. 316 (HOLOTIPO: ENCB. ...", debe decir "... Miguel Medina C. 1316 (HOLOTIPO: ENCB. ..." 